\title{
The relationship of aflatoxin bl and hepatocellular carcinoma: a mini review
}

\begin{abstract}
Hepatocellular carcinoma is one of the most important liver disease, been the fifth most common cause of cancer, and the second most common cause of cancer-related death worldwide. The presence of aflatoxin B1has become an important factor in identifying the genesis of the HCC. Mutation of the p53 tumor suppressor gene, upregulation of $\mathrm{H} 19$ gene and over-expression of E2F1 protein, have been address at the time to determine which factors are essential in hepatocarcinogenesis, and the synergistic relation with HBV favoring gene mutation.
\end{abstract}

Keywords: aflatoxin b1, hepatocellular carcinoma, liver cancer, Aspergillus flavus, Aspergillus parasiticus
Volume 3 Issue 6 - 2017

\author{
Salvador Lopez-Valdes, ${ }^{1,2}$ Medinilla-Cruz $M^{\prime}$ \\ 'Hospital General San Juan de Dios, Guatemala City, Guatemala, \\ Central America \\ ${ }^{2}$ Fundación Guatemalteca de Trasplante Hepatico, Guatemala \\ City, Guatemala, Central America
}

Correspondence: Salvador Lopez-Valdes, Fundahepa, $17 \mathrm{Av}$. 30-I6 Zona II, Las Charcas, Guatemala City, Guatemala, Central America, Tel 50224425046/50259902389.

E-mail slopezvaldes@gmail.com

Received: August 29, 2017 | Published: November 22, 2017
Abbreviations: AFB1, aflatoxin b1; AF, aspergillus flavus; AP, aspergillus parasiticus; FDA, food and drug administration; HCC, hepatocellular carcinoma; HBV, hepatitis b virus; AFB1-N7-Gua, 8,9 dihydri-8-(N7-guanyl)-9-hydroxy AFB1; AFB1-FABY, AFB1formamidopyrimidine; $\mathrm{G}$, guanine; $\mathrm{T}$, thymine

\section{Introduction}

Exposure to Aflatoxin is a major risk factor for the development of hepatocellular carcinoma (HCC), which is one of the most common malignancies worldwide. ${ }^{1,2}$ Aflatoxins are secondary metabolites of Aspergillus flavus (AF) and Aspergillus parasiticus (AP), fungus that develops under characteristic environmental conditions that are related to high moisture and temperature, and is associated to storage of maize, groundnuts, wheat, soy and rice; ${ }^{3}$ the Food and Drug Administration (FDA) has regulated aflatoxin levels for human consumption stablishing a level of $20 \mathrm{ngg}^{-1}(20 \mu \mathrm{g} / \mathrm{Kg})$ total aflatoxin (B1, B2, G1, G2). ${ }^{3,4}$ Williams et al, ${ }^{5}$ the risk of exposure to noninfectious food-borne toxins is estimated in 4.5 to 5.5 billion people worldwide, especially in countries located between $40^{\circ}$ North and $40^{\circ}$ South of the equator. In recent years, research has demonstrated that aflatoxin exposure is also linked to the occurrence of a specific mutation in the p53 tumor suppressor gene as mechanism of disease pathogenesis in $\mathrm{HCC}^{6}{ }^{6}$ The development of $\mathrm{HCC}$ is a multistage process with liver cell destruction, regeneration ending in fibrosis and cirrhosis, establishing a premalignant condition.?

\section{Discussion}

According to the International Agency for Research on Cancer, Aflatoxin B1 (AFB1) is a Group 1 carcinogen for $\mathrm{HCC},{ }^{8}$ which is the fifth most common cause cancer in males and seventh in females, with a male to female ratio of $4: 1$, carrying a poor prognosis in high incidence population with death within 12 months of diagnosis. ${ }^{3,9,10}$ Exposure of AFB1 increase susceptibility in the development of HCC, different studies have shown that airborne AF had higher concentrations in bakeries than in flour mills concluding that chronic occupational exposure of high concentrations $\left(487.2 \mathrm{cfu} / \mathrm{m}^{3}\right)$ cause significant elevation of AFB1 ${ }^{8} \mathrm{Bol}, \mathrm{EK}$, and collaborators evaluated the effects of heat on AFB1 in bakery products, baked under $220^{\circ} \mathrm{C}$ in different periods of time (between 20-35min) and different products (bread, cake and biscuits) using quantitative analysis of mycotoxins for zearaleone, ochratoxin and AFB1, using high performance liquid chromatography-tandem with diode array detection (HPLC-DAD), identifying that the heating process does not contribute to reduce the levels of AFB1 (36-40\%) in bread and biscuits, instead, cake was the only bakery product that reduced in $50 \%$ the levels of AFB1. The authors estimated that the theoretical total estimated exposure to AFB1 in pasta and bakery products was $6.9 \mathrm{ng} / \mathrm{kg}$ per day. ${ }^{11}$

\section{Carcinogenic effect of AFB I}

The main site of metabolism of AFB1 is the liver, but absorbed in the enterocytes of the small intestinal epithelium thru the cytochrome p450 enzymes (CYP 3A4, 3A5, 3A7 and 1A2) activating AFB1 into aflatoxin-8,9-exo-epoxide that is highly reactive with the $\mathrm{p} 53$ tumor suppressor gene, generating mutation at codon 249 (R249S; $249^{\text {ser }}$ mutation) in more than $50 \%$ of cases of HCC that were exposed to AFB1.,3,12 The binding with DNA forms 8,9 dihydri-8(N7-guanyl)-9-hydroxy AFB1 (AFB1-N7-Gua) a promutagenic adduct that can be converted in 2 secondary derivatives (an apurinic site and AFB1-formamidopyrimidine [AFB1-FABY]), this adduct produces a transverse mutation between guanine $(G)$ to thymine (T) with a frequency of 6times greater than AFB1-N7-Gua., ${ }^{3,13}$ After exposure and activation of AFB1, up-regulation of $\mathrm{H} 19$ gene (an imprinted oncofetal gene) is produced in HCC HepG2 cells with concentrations of AFB1 of $5-20 \mu \mathrm{g} / \mathrm{mL}$ and an expression level peak with concentration of $40 \mu \mathrm{g} / \mathrm{mL}$ AFB1. This can allowed the overexpression of $E 2 F 1$ protein promoting cell growth in HCC HepG2 cells and cellular invasion. ${ }^{14}$

Evidently AFB1 interact with different factors such as Hepatitis $\mathrm{B}$ virus (HBV), with which has a synergistic interaction favoring hepatocarcinogenesis. ${ }^{3,6}$ Patient who had HCC and HBV with a "high" AFB1 consumption had a 10-times higher mortality than those with "low" consumption. ${ }^{3}$ As mentioned above, the p53 tumor suppressor gene requires mutation at codon 249 to favor the onset of $\mathrm{HCC}$, therefore, it's important to note that HBV is not a sole factor to allow $249^{\text {ser }}$ mutations, but in the presence of HBV and AFB1 this mutation becomes more evident. ${ }^{13}$ MacGlynn et al. ${ }^{15}$ stated, that 
AFB1 is metabolized via the phase I and II detoxification pathways. Variation in two AFB1 detoxification genes: Epoxide Hydrolase (EPHX) and glutathione S-transferase M1 (GSTM1) were contrasted with AFB1-albumin adducts, presence of $\mathrm{HCC}$ and p53 codon 249 mutation, finding that mutant alleles of EPHX was overrepresented in HCC patients. However, the relationship changed in the presence of Hepatitis B virus surface antigen (HBsA), suggesting a synergistic effect allowing that individuals with mutant genotypes at EPHX and GSTM1 may be at greater risk in the development of HCC..$^{15}$ It is important to note that most cases of HCC occurs in the chronic liver disease or cirrhosis setting, thus cirrhosis is consider an emerging major global health problem. ${ }^{16}$ One of the most recent community base case-control study in Taiwan determined that the exposure to AFB1 thru a period of 9years may predict the development of HCC in chronic HBV carriers. ${ }^{?}$

\section{Conclusion}

In conclusion, Mutation of p53 suppressor gene (R249S; $249^{\text {ser }}$ mutation), ${ }^{3}$ up-regulation of $\mathrm{H} 19$ gene and over-expression of E2F1 protein ${ }^{14}$ have an important role in HCC development. Although AFB1 has been casually associated with $\mathrm{HCC},{ }^{3}$ the long exposure periods to this toxin may induce the development of $\mathrm{HCC}^{7}{ }^{7}$ World Health Organization has stated that it's a highly potent carcinogenic toxin for the liver, ${ }^{6}$ therefore it's important to establish AFB1 as an epidemiological priority for health authorities in regions where HCC has a high incidence.

\section{Acknowledgements}

None.

\section{Conflict of interest}

The authors declared that there are no conflicts of interest.

\section{References}

1. Chitapanarux T, Phornphutkul K. Risk Factors for the Development of Hepatocellular Carcinoma in Thailand. J Clin Transl Hepatol. 2015;3(3):182-188.

2. Salhab M, Canelo R. An overview of evidence-based management of hepatocellular carcinoma: A meta-analysis. $J$ Cancer Res Ther. 2011;7(4):463-475.
3. Kew MC. Aflatoxins as a cause of hepatocellular carcinoma. $J$ Gastrointestin Liver Dis. 2013;22(3):305-310.

4. Magnussen A, Parsi MA. Aflatoxins, hepatocellular carcinoma and public health. World J Gastroenterol. 2013;19(10):1508-1512.

5. Williams JH, Phillips TD, Jolly PE, et al. Human aflatoxin in developing countries: a review of toxicology, exposure, potential health consequences, and interventions. Am J Clin Nutr. 2004;80(5):1106-1122.

6. Qi LN, Bai T, Chen ZS, et al. The p53 mutation spectrum in hepatocellular carcinoma from Guangxi, China: Role of chronic hepatitis B virus infection and aflatoxin B1 exposure. Liver Int. 2015;35(3):999-1009.

7. Chu YJ, Yang HI, Wu HC, et al. Aflatoxin B1 exposure increases the risk of cirrhosis and hepatocellular carcinoma in chronic hepatitis B virus carriers. Int J Cancer. 2017;141(4):711-720.

8. Saad-Hussein A, Taha MM, Beshir S, et al. Carcinogenic effects of aflatoxin B1 among wheat handlers. Int $J$ Occup Environ Health. 2014;20(3):215-219.

9. Wang CC, Iyer SG, Low JK, et al. Perioperative factors affecting longterm outcomes of 473 consecutive patients undergoing hepatectomy for hepatocellular carcinoma. Ann Surg Oncol. 2009;16(7):1832-1842.

10. Mazzanti R, Arena U, Tassi R. Hepatocellular carcinoma: Where are we? World J Exp Med. 2016;6(1):21-36.

11. Bol EK, Araujo L, Veras FF, et al. Estimated exposure to zearalenone, ochratoxin A and aflatoxin B1 through the consume of bakery products and pasta considering effects of food processing. Food Chem Toxicol. 2016;89:85-91.

12. Ross RK, Yuan JM, Yu MC, et al. Urinary aflatoxin biomarkers and risk of hepatocellular carcinoma. Lancet. 1992;339(8799):943-946.

13. Wild CP, Turner PC. The toxicology of aflatoxins as a basis for public health decisions. Mutagenesis. 2002;17(6):471-481.

14. Lv J, Yu YQ, Li SQ, et al. Aflatoxin B1 promotes cell growth and invasion in hepatocellular carcinoma HepG2 cells through $\mathrm{H} 19$ and E2F1. Asian Pac J Cancer Prev. 2014;15(6):2565-2570.

15. McGlynn KA, Rosvold EA, Lustbader ED, et al. Susceptibility to hepatocellular carcinoma is associated with genetic variation in the enzymatic detoxification of aflatoxin B1. Proc Natl Acad Sci. 1995;92(6):2384-2387.

16. Sakamoto M. Pathology of early hepatocellular carcinoma. Hepatol Res. 2007;37(Suppl 2):S135-S138. 